\title{
Can Steroids plus Surgery Become a First-Line Treatment of Idiopathic Granulomatous Mastitis?
}

\author{
Hasan Karanlik $^{\mathrm{a}} \quad$ Ilker Ozgur $^{\mathrm{b}} \quad$ Serife Simsek $^{\mathrm{a}} \quad$ Alisan Fathalizadeh $^{\mathrm{a}} \quad$ Mustafa Tukenmez $^{\mathrm{c}}$ \\ Dilek Sahin $^{d}$ Memduh Dursun $^{\mathrm{e}}$ Sidika Kurula
}

a Surgical Oncology Unit, Institute of Oncology, Istanbul University, Turkey

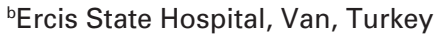

c Department of General Surgery, Istanbul Medical Faculty, Istanbul University, Turkey

d Department of Radiology, Institute of Oncology, Istanbul University, Turkey

${ }^{\text {eDepartment }}$ of Radiology, Istanbul Medical Faculty, Istanbul University, Turkey

\section{Keywords}

Idiopathic granulomatous mastitis .

Preoperative steroid therapy · Surgical excision

\section{Summary}

Background: The aim of this study is to compare the clinical course of idiopathic granulomatous mastitis (IGM) treated with low-dose oral corticosteroid therapy alone as opposed to treatment with low-dose corticosteroid therapy followed by surgery. Patients and Methods: 37 patients were treated with an approach that consisted of methylprednisolone at a dose of $0.5 \mathrm{mg} / \mathrm{kg} / \mathrm{day}$ followed by wide excision, and 23 patients were treated with an approach that consisted only of methylprednisolone. The treatment efficacy was compared between the two groups. Results: Clinical and radiological regression was reported in all patients with steroid therapy, and the regression rate had a median of $75 \%$ (25-100\%). No recurrence was observed in patients who were treated with wide surgical excision after steroid therapy during the median follow-up period of 38 (22-78) months. The control group of 23 patients was treated only with steroid therapy, and 7 (30\%) of these patients experienced recurrence in the follow-up period ( $p<0.001)$. Conclusions: Steroid therapy was effective in the treatment of IGM by reducing the lesion size and extent. With regard to the current treatment options available for IGM, surgical excision after steroid therapy seems the better treatment option compared to steroid therapy without surgical excision. This treatment sequence reduces the rate of recurrence.

\section{Introduction}

Idiopathic granulomatous mastitis (IGM) is a rare inflammatory breast disease of unknown etiology. Although it usually presents with sinus formation and abscesses, it may mimic the clinical characteristics of breast cancer [1-3]. A definitive diagnosis can only be established and confirmed by histopathology and is essential in order to differentiate this condition from breast cancer. Therefore, careful attention is necessary when making the diagnosis so that patients with IGM can be protected from unnecessary radical mastectomies $[4,5]$.

The treatment of IGM is controversial. Use of antibiotics or corticosteroids and wide excision of the affected tissue have been reported as treatment options [1, 6-8]. However, there is no consensus about the most appropriate therapy in these patients. Although wide excision of the mass was traditionally performed in the past, this was followed by a high rate of recurrence, skin ulceration, abscess formation, fistulae formation, and wound infection [1, 4, 9]. Corticosteroid therapy is effective in decreasing the granulomatous mass in this disease $[4,10,11]$. Many of the previous reports on IGM have focused on the histological and radiological features; however, few reports have been published on the progress of this disease when treated with corticosteroids [12-14]. The aim of this study was to investigate the clinical course of IGM treated with corticosteroids and to evaluate the results of standardized combined therapy with corticosteroid followed by surgery compared to treatment by corticosteroid alone.

\begin{tabular}{ll}
\hline KARGER & @ 2014 S. Karger GmbH, Freiburg \\
1661-3791/14/0095-0338\$39.50/0 \\
Fax+497614520714 \\
$\begin{array}{l}\text { Information@Karger.com } \\
\text { www.karger.com }\end{array}$ & $\begin{array}{l}\text { Accessible online at: } \\
\text { www.karger.com/brc }\end{array}$
\end{tabular}


Table 1. Clinical characteristics of the IGM patients

\begin{tabular}{llll}
\hline Patient characteristics & $\begin{array}{l}\text { Steroid followed } \\
\text { by surgery, } \mathrm{n}=37\end{array}$ & $\begin{array}{l}\text { Steroid alone, } \\
\mathrm{n}=23\end{array}$ & $\mathrm{p}$ \\
\hline $\begin{array}{l}\text { Median age, years (range) } \\
\text { Side, N (\%) }\end{array}$ & $35(18-58)$ & $34(23-57)$ & $\mathrm{NS}$ \\
$\quad$ Right & $20(54 \%)$ & $12(52 \%)$ & $\mathrm{NS}$ \\
$\quad$ Left & $16(43 \%)$ & $10(43 \%)$ & \\
$\quad$ Bilateral & $1(3 \%)$ & $1(1 \%)$ & \\
Physical examination, N (\%) & $14(38 \%)$ & $10(43 \%)$ & NS \\
$\quad$ Mass & $10(27 \%)$ & $5(22 \%)$ & \\
Abscess & $6(16 \%)$ & $3(13 \%)$ & \\
Fistula & $7(19 \%)$ & $5(22 \%)$ & NS \\
$\quad$ Mass + fistula \pm abscess & & & NS \\
Education level, N (\%) & $27(73 \%)$ & $16(70 \%)$ & NS \\
Primary school or less & $10(27 \%)$ & $7(30 \%)$ & NS \\
High school or higher & $24(2-72)$ & $26(0-60)$ & NS \\
Time of breastfeeding, months (range) & $2(0-2)$ & $2(0-5)$ & NS \\
Parity, median (range) & $12(32 \%)$ & $7(30 \%)$ & NS \\
Oral contraceptive use, N (\%) & $2(1-21)$ & $3(2-17)$ & \\
Time since last delivery, years (range) & $7(19 \%)$ & $5(22 \%)$ & \\
Smoking, N (\%) & & & \\
\hline NS = Not significant. & &
\end{tabular}

Table 2. Radiological features of the IGM patients

\begin{tabular}{llll}
\hline Radiographic findings & $\begin{array}{l}\text { Steroid followed } \\
\text { by surgery, } \mathrm{N}(\%)\end{array}$ & $\begin{array}{l}\text { Steroid alone, } \\
\mathrm{N}(\%)\end{array}$ & $\mathrm{p}$ \\
\hline Mammographic findings (n = 22 patiens) & & & \\
$\quad$ Asymmetric density & $6(46 \%)$ & $4(44 \%)$ & NS \\
$\quad$ Solitary or multiple circumscribed masses & $2(15 \%)$ & $1(11 \%)$ & \\
$\quad$ Architectural distortion & $2(15 \%)$ & $1(11 \%)$ & \\
$\quad$ Ill-defined mass & $1(7 \%)$ & $1(11 \%)$ & NS \\
$\quad$ Normal & $2(15 \%)$ & $2(22 \%)$ & \\
Ultrasound findings (n = 60 patients) & $24(65 \%)$ & $15(65 \%)$ & \\
$\quad$ Hypoechoic lesions & $10(27 \%)$ & $6(26 \%)$ & \\
$\quad$ Abscess formation with fistula & $3(8 \%)$ & $2(9 \%)$ & \\
$\quad$ Parenchymal heterogeneity & $18(62 \%)$ & $9(64 \%)$ & \\
MRI findings (n = 43 patients) & $14(48 \%)$ & $6(43 \%)$ & \\
$\quad$ Solitary mass & $11(38 \%)$ & $5(36 \%)$ & \\
$\quad \begin{array}{l}\text { Parenchymal asymmetry } \\
\text { Parenchymal distortion }\end{array}$ &
\end{tabular}

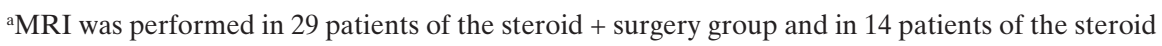
alone group.

\section{Materials and Methods}

This prospective, non-randomized observational study was conducted in the Surgical Oncology Unit at the Institute of Oncology at Istanbul University and included 60 women with IGM. Our institution has been performing combination therapy since 2001.37 patients were treated with low-dose steroid therapy followed by surgery between January 2007 and December 2011. 23 patients who were treated with only low-dose steroid therapy between January 2012 and May 2013 were taken as a control group. All patients were treated sequentially, and the two groups were compared. Patients were eligible to participate if they were adult women ( $\geq 18$ years old) who were diagnosed with IGM histopathologically, if they were able to come to the hospital for weekly examinations, had agreed to participate and had given their written informed consent. The study was approved by the Institutional Review Board at Istanbul University. A surgeon explained the study before starting the steroid therapy and determined the patient's intent to cooperate during participation.

The lesions were marked with a marker pen and photographed before steroid therapy. All of the patients were then diagnosed with IGM by core needle or incisional biopsy, after which they received 6-8 weeks of steroid therapy. Methylprednisolone (Prednol®, Mustafa Nevzat, Istanbul, Turkey) was started at a dose of $0.5 \mathrm{mg} / \mathrm{kg} /$ day for $2-4$ weeks and then tapered down slowly for 4 weeks.

Patients with significant mass shrinkage after the first week of steroid therapy underwent sonographically guided placement of a metallic marker $(n=5)$ in the center of the lesion, to facilitate later localization of the initial lesion site. Preoperative mammographically guided needle localization of the metallic marker was performed in patients who had non- 

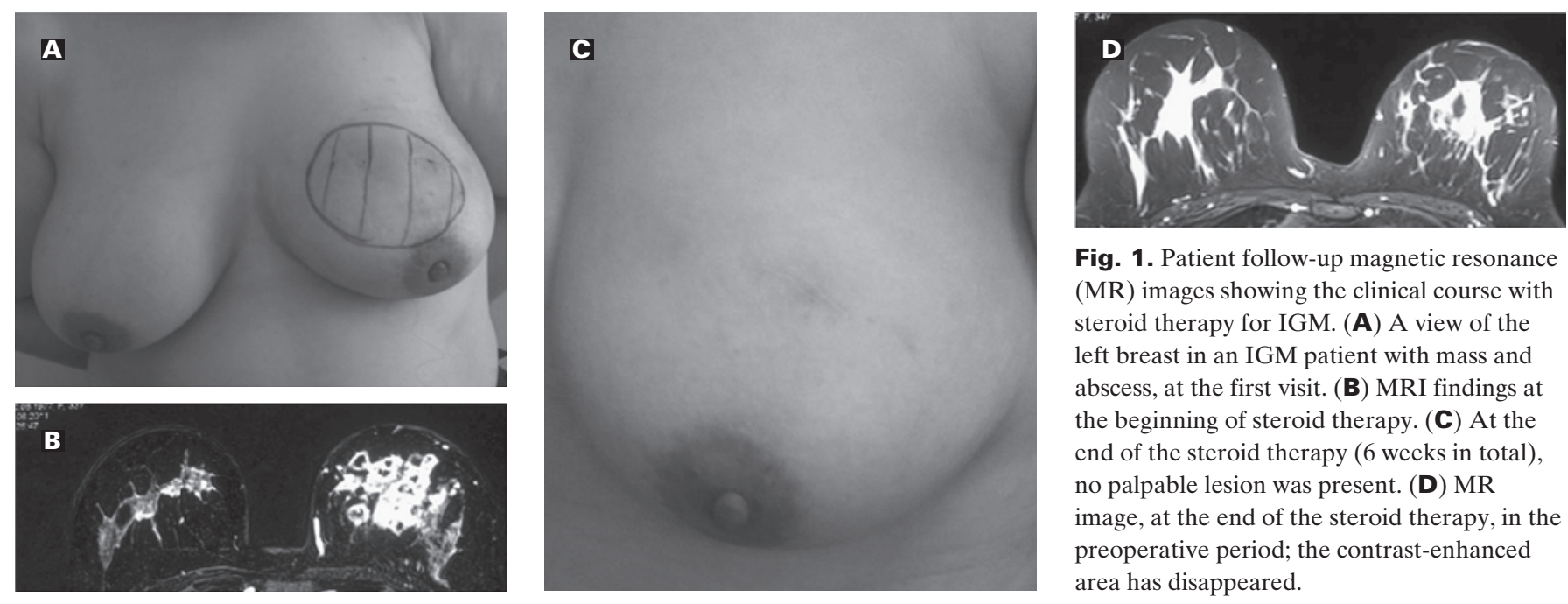

Fig. 1. Patient follow-up magnetic resonance (MR) images showing the clinical course with steroid therapy for IGM. (A) A view of the left breast in an IGM patient with mass and abscess, at the first visit. (B) MRI findings at the beginning of steroid therapy. (C) At the end of the steroid therapy (6 weeks in total), no palpable lesion was present. (D) MR image, at the end of the steroid therapy, in the preoperative period; the contrast-enhanced area has disappeared.
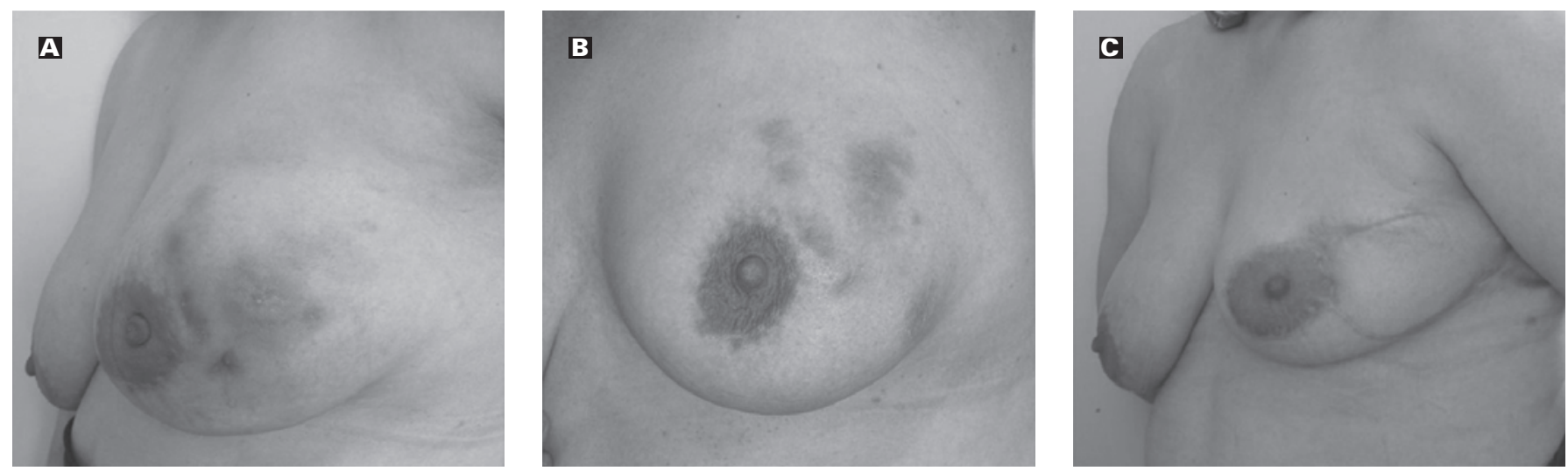

Fig. 2. (A) View of the left breast in an IGM patient with mass and fistula formation. (B) At the end of the steroid therapy (32 mg/day for 4 weeks, tapered down every following week, 24, 16, 8, $4 \mathrm{mg}$ and stopped). (C) After wide excision.

palpable lesions $(\mathrm{n}=4)$ for surgical orientation. In other patients, wide excision was performed.

Microsoft Excel software (Microsoft Luxembourg S.a.r.l., Luxembourg) was used to record the data. Comparisons between continuous variables were made by t-test or the Mann-Whitney U test. Comparisons between categorical variables were based on Pearson's $\chi$-square test or Fisher's exact test. In all statistical analyses, a $p$ value of $<0.05$ was considered significant. Data analysis was carried out with the Statistical Package for Social Sciences (SPSS) version 15.0 (SPSS, Chicago, IL, USA).

\section{Results}

\section{Clinical Characteristics}

The clinical characteristics of all patients with IGM are shown in table 1 . The median duration between the onset of symptoms and the patient presenting to the hospital was 6 months (2-14 months). 12 patients $(20 \%)$ had a history of nicotine addiction. All patients came from a low socio-economic class. 24 patients $(40 \%)$ had unilateral, extra-areolar breast masses, and 8 of them also had palpable axillary lymph nodes.
The median size of the mass lesions was $5 \mathrm{~cm}$, with a range of $1-13 \mathrm{~cm}$. Furthermore, 15 patients $(25 \%)$ had acute abscess formation. A summary of the radiologic findings is shown in table 2 .

\section{Treatment and Outcome}

Clinical and radiological regression was reported in all patients with steroid therapy, and the rate of response had a median of $75 \%(25-100 \%)$. Complete clinical and radiological regression was observed in 38 patients (63\%). 37 patients were treated with wide surgical excision for possible inflammatory granulomatous lesions within 7-21 days after steroid therapy, and further recurrence was not observed during the follow-up of median 38 (22-78) months. A control group of 23 patients was treated with steroid therapy alone. Recurrence was observed in 7 of the $23(30 \%)$ patients with a follow-up of median 12 (2-18) months, and these patients were later treated with surgical excision $(\mathrm{p}<0.001)$. Figures 1 and 2 show the management and treatment response of the IGM patients. 
Following steroid therapy, a cushingoid appearance and hirsutism was reported in $4(7 \%)$ patients. In these patients, methylprednisolone was administered at a dose of $0.5 \mathrm{mg} / \mathrm{kg} /$ day for 4 weeks. No hypertension or glucose intolerance was observed in any patient. The postoperative period was uneventful in all of the study patients. The breast cosmetic results at the end of the treatment were described as good to excellent by $95 \%$ of the patients, without recurrence according to patient evaluations.

\section{Discussion}

Surgical resection and corticosteroid administration have been previously reported for the treatment of IGM $[1,4,6,7]$. However, no consensus treatment strategy has been reported due to the rarity of this disease. Patients usually present with complaints of a hard breast mass and sometimes of pain warmth, and a fistula at the site [15]. A mastectomy is mistakenly performed in some cases because the mass presents with clinical symptoms that may mimic breast cancer, demonstrating the increased importance of correct diagnosis of this condition [16-20].

The management of IGM remains controversial [1, 3, 4, 11, 21-25]. Wide excision of the mass was performed traditionally, but surgical excision was recognized to result in high rates of recurrence, skin ulceration, abscess formation, fistulae formation, and wound infection $[1,4,11,13]$. Surgical excision can be therapeutic when performed with negative surgical margins. However, in patients with extensive or acute inflammatory disease, performing surgical excision with negative margins, no resulting wound problems, and acceptable cosmetic outcomes may be rather difficult. We advocated in our previous publication that surgical excision is the preferable approach because of possible steroid side effects according to the publications that studied high steroid doses $[1,10$, $11,13]$. Steroid treatment decreases the lesion dimensions and augments complete healing after excision [22]. Early recognition and administration of low-dose steroid treatment might prevent repetitive, deforming breast biopsies. Satisfactory results have been reported with high doses of prednisone (60 $\mathrm{mg} /$ day for 2 weeks), yet there is a reluctance to use high doses of steroids due to possible side effects such as glucose intolerance and cushingoid features [22, 26, 27]. Our standard treatment dose was $0.5 \mathrm{mg} / \mathrm{kg} /$ day methylprednisolone (maximum $32 \mathrm{mg} /$ day) for 2 weeks, and thereafter the dose was slowly tapered and the therapy was stopped 1 month later. We had fairly satisfactory results with this dose, with no serious side effects.

The best method to evaluate treatment outcomes during steroid therapy for IGM has not yet been defined [4, 11, 15, 28]. In our study, the steroid treatment outcomes were evaluated by palpation and ultrasonography and, in some patients, by contrast magnetic resonance imaging (MRI). We found that $63 \%$ of our patients had radiological complete response after low-dose steroid therapy for 2 months; half of these demonstrated complete response as confirmed by MRI. Interestingly, the diagnosis of IGM was definitively confirmed by histopathological analysis following surgical resection in all patients, including those who demonstrated complete radiological response.

Combined therapy consisting of surgery following steroid therapy was used in our study. 37 patients received wide excisions irrespective of whether they showed total or partial response to steroid therapy. Interestingly, histopathological assessment still demonstrated the diagnosis of IGM in patients with total regression and no residual lesion after steroid therapy. Thus, this demonstrated that, in order to prevent a potential recurrence, it may be important to remove the entire lesion area even if the MRI demonstrated no lesion after steroid therapy.

Since it is widely accepted that IGM is a possible autoimmune disease with an immune response against breast ductal epithelial cells, we hypothesized that the residual area or previous lesion bed that was excised after steroid therapy may be the area responsible for the autoimmunity against breast epithelial cells and IGM relapses. Our patients undergoing steroid and surgical therapy experienced no relapses when followed up for a mean time of 38 (22-78) months, thereby potentially supporting the aforementioned hypothesis. We believe that if there is an autoimmune etiology in IGM, then we must first approach the IGM lesion as an antigenic target which may be responsible for an immune response specifically against breast ductal epithelial cells. The second aim is the identification of optimal methods to totally eliminate the lesion areas with combination therapies. It has been reported in some papers that most of the patients showed resolution of the disease with steroid therapy over a certain time period, but disease persistence or recurrence was observed with steroid tapers [22, 24, 25, 29]. In our study, we observed relapse in 7 patients $(30 \%)$ who received a steroid taper alone. The combined therapy of steroid treatment plus excision thus demonstrated an overall better response rate among our patients, with better outcomes when compared to a control of just steroid treatment alone. In comparing our results with those of other previously published articles, we found that the combined therapy approach was superior to steroid therapy or surgical excision alone [1, 4, 22].

In conclusion, steroid therapy followed by surgery may be recommended as the first-line therapy for IGM in all cases. This treatment sequence would potentially reduce the size of the surgical scar and the recurrence rates. Complete response detected ultrasonographically or by MRI can be observed with steroid therapy; however, this does not ensure that no lesion is present histopathologically. Therefore, we propose systemic therapy with corticosteroids followed by wide excision as the recommended first-line treatment strategy for IGM. We believe that before larger-scale and more comprehensive 
multi-model, multi-year studies are undertaken, such a firstorder study can provide invaluable information in the planning of future research projects.

\section{Disclosure Statement}

The authors of this article identify that there is no conflict of interest to claim.

\section{Ethical Approval}

This study meets the standards of ethical approval of the University of Istanbul.

\section{References}

1 Asoglu O, Ozmen V, Karanlik H, Tunaci M, Cabioglu N, Igci A, Selcuk UE, Kecer M: Feasibility of surgical management in patients with granulomatous mastitis. Breast J 2005;11:108-114.

- Ayeva-Derman M, Perrotin F, Lefrancq T, Roy F, Lansac J, Body G: Idiopathic granulomatous mastitis: review of the literature illustrated by four cases. J Gynecol Obstet Biol Reprod 1999;28:800-807.

3 Mohammed S, Statz A, Lacross JS, Lassinger BK, Contreras A, Gutierrez C, Bonefas E, Liscum KR, Silberfein EJ: Granulomatous mastitis: a 10 year experience from a large inner city county hospital. J Surg Res 2013;184:299-303.

4 Sakurai K, Fujisaki S, Enomoto K, Amano S, Sugitani M: Evaluation of follow-up strategies for corticosteroid therapy of idiopathic granulomatous mastitis. Surg Today 2011;41:333-337.

5 Carmalt HL, Ramsey-Stewart G: Granulomatous mastitis. Med J Aust 1981;1:356-359.

6 Dixon JM, Chetty U: Diagnosis and treatment of granulomatous mastitis. Br J Surg 1995;82:11431144.

7 Erhan Y, Veral A, Kara E, Ozdemir N, Kapkac M, Ozdedeli E, Yilmaz R, Koyuncu A, Erhan Y, Ozbal O: A clinicopathologic study of a rare clinical entity mimicking breast carcinoma: idiopathic granulomatous mastitis. Breast 2000;9:52-56.

$>8$ Gal-Gombos EC, Esserman LE, Odzer SL, Weisberg S, Wilson C, Poppiti RJ: Granulomatous mastitis: diagnosis by ultrasound-guided core biopsy. Breast J 2001;7:129-130.

9 Fletcher A, Magrath IM, Riddle RH, Talbot IC: Granulomatous mastitis: report of seven cases. J Clin Pathol 1982;35:38-42.

10 DeHertogh D, Rossof A, Harris AA, Economou SG: Prednisone management of granulomatous mastitis. N Engl J Med 1980;303:799-800.
11 Sato N, Yamashita H, Kozaki N, Watanabe Y, Ohtsuka T, Kuroki S, Nakafusa Y, Ota M, Chijiiwa $\mathrm{K}$, Tanaka M: Granulomatous mastitis diagnosed and followed up by fine-needle aspiration cytology, and successfully treated by corticosteroid therapy: report of a case. Surg Today 1996;26:730-733.

12 Han BK, Choe YH, Park JM, Moon WK, Ko YH, Yang JH, Nam SJ: Granulomatous mastitis: mammographic and sonographic appearances. AJR Am J Roentgenol 1999;173:317-320.

13 Jorgensen MB, Nielsen DM: Diagnosis and treatment of granulomatous mastitis. Am J Med 1992; 93:97-101.

14 Dursun M, Yilmaz S, Yahyayev A, Salmaslioglu A, Yavuz E, Igci A, Acunas G, Tunacı M: Multimodality imaging features of idiopathic granulomatous mastitis: outcome of 12 years of experience. Radiol Med 2012;117:529-538.

15 Firzah A, Ariza Z, Arni T, Hisham AN: Chronic granulomatous mastitis: diagnostic and therapeutic considerations. World J Surg 2003;27:515-518.

16 Erhan Y, Veral A, Kara E, Ozdemir N, Kapkac M, Ozdedeli E, Yilmaz R, Koyuncu A, Erhan Y, Ozbal O: A clinicopathologic study of a rare clinical entity mimicking breast carcinoma: idiopathic granulomatous mastitis. Breast 2000;9:52-56.

17 Heer R, Shrimankar J, Griffith CDM: Granulomatous mastitis can mimic breast cancer on clinical, radiological or cytological examination: a cautionary tale. Breast 2003;12:283-286.

18 Ozturk M, Mavili E, Kahriman G, Akcan AC, Ozturk F: Granulomatous mastitis: radiological findings. Acta Radiol 2007;48:150-155.

19 Marchant DJ: Inflammation of the breast. Obstet Gynecol Clin N Am 2002;29:89-102.

20 Moore GE: Diagnosis and treatment of granulomatous mastitis. Br J Surg 1995;82:1002.

21 Salam IM, Alhomsi MF, Daniel MF, Sim AJ: Diagnosis and treatment of granulomatous mastitis. $\mathrm{Br}$ J Surg 1995;82:214.
22 Erozgen F, Ersoy YE, Akaydin M, Memmi N, Celik AS, Celebi F, Guzey D, Kaplan R: Corticosteroid treatment and timing of surgery in idiopathic granulomatous mastitis confusing with breast carcinoma. Breast Cancer Res Treat 2010;123:447-452.

23 Koray O, Ahmet D, Ozgur T: Granulomatous mastitis: clinical, pathological features, and management. Breast J 2010;16:176

24 Gurleyik G, Aktekin A, Aker F, Karagulle H, Saglamc A: Medical and surgical treatment of idiopathic granulomatous lobular mastitis: A benign inflammatory disease mimicking invasive carcinoma. J Breast Cancer 2012;15:119-123.

25 Ozel L, Unal A, Unal E, Kara M, Erdoğdu E, Krand O, Güneş P, Karagül H, Demiral S, Titiz MI: Granulomatous mastitis: is it an autoimmune disease? Diagnostic and therapeutic dilemmas. Surg Today 2012;42:729-733.

26 Donn W, Rebbek P, Wilson C, Gilks CB: Idiopathic granulomatous mastitis. A report of three cases and review of the literature. Arch Pathol Lab Med 1994;118:822-825.

27 Akcan A, Akyildiz H, Deneme MA, Akgun H, Aritas Y: Granulomatous lobular mastitis: a complex diagnostic and therapeutic problem. World J Surg 2006;30:1403-1409.

28 Maffini F, Baldini F, Bassi F, Luini A, Viale G: Systemic therapy as a first choice treatment for idiopathic granulomatous mastitis. J Cutan Pathol 2009;36:689-691.

29 Kuba S, Yamaguchi J, Ohtani H, Shimokawa I, Maeda S, Kanematsu T: Vacuum-assisted biopsy and steroid therapy for granulomatous lobular mastitis: report of three cases. Surg Today 2009; 39:695-699. 